\title{
Arbitraje de inversión en Colombia
}

\author{
Eduardo Zuleta
}

\begin{abstract}
Sumario
1. Introducción. 1.1 Una distinción fundamental: el arbitraje internacional de inversión y el arbitraje comercial internacional. 1.2 La manifestación del consentimiento para acudir a arbitraje. 1.2.1 Acuerdo directo entre el Estado receptor de la inversión y el inversionista. 1.2.2 Oferta de arbitraje formulada en la legislación nacional. 1.2.3 Tratados internacionales. 2.2 Las partes en el proceso. 2.2.1 Inversionista Extranjero. 2.2.2 El Estado. 2.3 Objeto de la controversia. 2.4 Derecho aplicable. 2.5 El procedimiento arbitral. 3. El arbitraje de inversión y la Ley 1563 de 2012. 4. Conclusión.
\end{abstract}

\section{INTRODUCCIÓN}

Colombia tiene actualmente una política de Estado a favor de la promoción de la inversión extranjera directa; así lo ha dado a entender el propio Presidente de la República quien, por sólo mencionar un ejemplo, afirmó el pasado 25 de mayo de 2012 que "Colombia está abierta a la inversión [...] Colombia es un país muy atractivo y eso significa que el dinero que aquí invierte se traduce en empleo en Colombia, en crecimiento económico, y eso es lo que queremos promover"1. La política del gobierno actual sigue en esta materia la línea de administraciones anteriores, que también se preocuparon por atraer inversionistas extranjeros al país.

1. Presidencia de la República de Colombia - Sistema Informativo del Gobierno, Nota de prensa, 25 de mayo de 2012. Disponible en Web. hitp:/wsp.presidencia.gov.co/Prensa/2012/Mayo/Paginas/ 20120525 02.aspx (Consulta: I5 de septiembre de 2012). 
Entre los resultados normativos de esa política se destaca el Decreto 2080 del 18 de octubre de 2000, que contiene el régimen general de inversión de capital del exterior en Colombia y de capital colombiano en el exterior ${ }^{2}$.En el ámbito internacional, en los últimos años, el Estado colombiano ha celebrado múltiples tratados bilaterales de inversión (en adelante TBI) y en capítulos de inversión de tratados de libre comercio (en adelante TLC), que usualmente otorgan a los inversionistas por ellos protegidos ciertas garantías bajo el derecho internacional, tales como el derecho a recibir un trato no menos favorable que el otorgado a inversionistas nacionales (trato nacional) o provenientes de terceros países (trato nación más favorecida), a recibir un trato justo y equitativo, y a ser indemnizados en caso de expropiación, entre otros.

Además de estas disposiciones sustantivas, los instrumentos en mención suelen prever la posibilidad de resolver mediante arbitraje internacional las controversias surgidas entre inversionistas extranjeros protegidos y el Estado receptor de la inversión.

Ahora bien, ¿qué tienen que ver estos arbitrajes, llamados "de inversión", con la Ley 1563 de 2012? La respuesta a este interrogante no resulta obvia. Más aún, muy seguramente algunos lectores encontrarán extraño hallar un capítulo sobre arbitraje de inversión en un comentario al nuevo estatuto arbitral colombiano, ya que, por una parte, la Ley no trata expresamente la materia y, por otra, el arbitraje de inversión suele estar previsto como mecanismo de resolución de disputas en los TBI y en TLC.

Para entender por qué la Ley 1563 de 2012 puede ser aplicable a ciertos arbitrajes de inversión, es necesario establecer la diferencia conceptual entre el arbitraje comercial internacional y el arbitraje de inversión (II), para analizar el campo de aplicación de la sección de arbitraje internacional de la Ley 1563 de 2012 (III).

2. Véase: Decreto 2080 del 18 de octubre del 2000 . 


\subsection{Una distinción fundamental: el arbitraje internacional de inversión y el arbitraje comercial internacional}

El arbitraje internacional es un género que comprende especies que no siempre resultan fáciles de distinguir. Dos de ellas, que corresponden al objeto de estudio del presente trabajo, son el arbitraje de inversión y el arbitraje comercial internacional. Uno y otros son arbitrajes internacionales, pero son especies diferentes. La distinción entre ambos tipos de arbitraje puede trazarse a partir de cinco criterios fundamentales, a saber: la manifestación del consentimiento para acudir a arbitraje (2.1); las partes en el proceso (2.2); el objeto de la controversia (2.3); el derecho aplicable (2.4); y el procedimiento arbitral (2.5).

\subsection{La manifestación del consentimiento para acudir a arbitraje}

Tanto el arbitraje comercial internacional como el arbitraje de inversión encuentran su fundamento en el consentimiento manifestado por las partes para acudir a arbitraje ${ }^{3}$. La presente sección se concentrará en la formación del acuerdo de arbitraje en tratándose de arbitrajes de inversión. La manifestación del consentimiento para acudir a arbitraje de inversión se puede materializar a través de distintos medios, siendo los principales: un acuerdo directo entre el Estado receptor de la inversión y el inversionista (2.1.1), una oferta de arbitraje formulada en la legislación nacional (2.1.2) o un tratado internacional (2.1.3) ${ }^{4}$.

3. Véase: Dolzer, Rudolf \& Schreuer, Christoph, Principles of International investment Law, Oxford University Press, 2008, p. 238.

4. Véase: PAulsson, Jan, "Arbitration without Privity", en ICSID Revicw, No. 10, 1999, pp. 232-234; Selurcuer, Chrisioph, The ICSID Convention: A Commentary, Cambridge University Press, 2001, pp. 193-224. 


\subsubsection{Acuerdo directo entre el Estado receptor de la inversión y el inversionista}

$\mathrm{Al}$ igual que en el arbitraje comercial internacional, en el arbitraje de inversión el consentimiento de las partes para acudir a arbitraje se puede encontrar en una cláusula compromisoria o en un compromiso. En efecto, en los denominados acuerdos o contratos de inversión, celebrados entre el Estado receptor de la inversión y un inversionista extranjero, las partes pueden incluir una estipulación contractual por la cual someten a arbitraje las diferencias que en relación con la inversión pudieren suscitarse entre ellas en el futuro. De igual manera, el acuerdo directo para llevar a arbitraje una controversia de inversión podría tomar la forma de un compromiso, celebrado después del surgimiento de la controversia ${ }^{5}$. En cualquier caso, en la práctica, los acuerdos directos de arbitraje de inversión suelen tomar la forma de una cláusula compromisoria inserta en un contrato de inversión $n^{6}$. Sobre esta forma de manifestar el consentimiento es preciso hacer tres observaciones.

Primero, se debe resaltar que el acuerdo directo de inversión no necesariamente tiene que estar plasmado en un único instrumento. Piénsese, por ejemplo, en una oferta de inversión de un

5. Véase: Dolzer, Rudolf \& SCItReuer, Christoph, Principles of International Imestment Law, Oxford University Press, 2008, p. 239.

6. Para algunos ejemplos de arbitrajes en que la jurisdicción del tribunal estaba fundada en un pacto arbitral inserto en un contrato de inversión, véase: Adriano Gantella c. Ivony Coast, Laudo, Caso CIADI No. ARB 74/1, 29 de agosto de 1977; Naiser Bauxile c. Jamaica, Decisión de jurisdicción y competencia, Caso CIADI No. ARB/74/3, 5 de julio de 1975; AGIP S.p.A. c. Repuiblica Popular del Congo, Laudo, Caso CIADI No. ARB/77/1, 30 de noviembre de 1979; S.A.R.L. Benvemuti \& Bonfant c. Republica Popular del Congo, Laudo, Caso ClADI No. ARB/77/2, 8 de julio de 1980; Amco Asia Corp. c. Indonesia, Decisión sobre jurisdicción, Caso CIADI No. ARB/81/1, 25 de septicmbre de 1983; Kläckner Inchustrie-Anlagen GmbH et. al. c. Camerrin \& Société Camerounaise des Engrais, Laudo, Caso CIADI No. ARB/81/2, 21 de octubre de 1983: Société Ones Africuine des Bézons Industriels c. Senegal. Laudo, Caso CIADI No. ARB/82/1, 25 de febrero de 1988; Liberian East Timber Corp. c. Liberia, Laudo, Caso CIADI No. ARB/83/2, 31 de marzo de 1986; Atlantic Triton Company Lud. c. Guinea, Laudo, Caso CIADI No. ARB/84/I, 21 de abril de 1986; Vaccum Salt Products Ltd. c, Ghana, Laudo, Caso CIADI No. ARB/92/1, 16 de febrero de 1994; Mobil Oil Corp. et. al. c. Nueva Zelanda, Caso CIADI No. ARB/87/2, caso presentado el 15 de abril de 1987; Holiday Inns S.A. et. àl. c. Marriccos, Caso CIADI No. ARB/72/1, caso presentado el 13 de enero de 1972. Sobre este último caso, véase: Lalive, Pierre, "The First 'Worid Bank' Arbitration", en British Year Book of International Law, No. 51, 1980, pp. 123-162. Los casos listados fueron tomados de: Conferencia de las Naciones Unidas sobre Comercio y Desarrollo, Dispute Settlement, International Centre for Settlement of Investment Disputes, 2.3 Consent to Arbitration, UNCTAD/EDM/Misc.232/Add.2, p. 7. 
inversionista extranjero que es aceptada por la autoridad competente en el Estado receptor de la inversión, como ocurrió en el caso en Amco c. Indonesia ${ }^{7}$. Asimismo, un acuerdo directo para arbitrar diferencias de inversión podría formarse si las partes hacen referencia a otro instrumento que contenga una disposición relativa a arbitraje de inversión ${ }^{8}$.

Segundo, la redacción de un pacto arbitral nunca es tarea fácil. Tratándose de pactos para arbitraje de inversión, habría una dificultad adicional, consistente en establecer cuándo es posible celebrar tal acuerdo. En efecto, la mera calificación que las partes en un contrato comercial hagan de un arbitraje como "de inversión" no lo torna tal ni les permite a los contratantes señalar que el procedimiento se regirá por un reglamento diseñado exclusivamente para ese tipo de arbitrajes. Cuando sea posible pactar arbitraje de inversión, sería recomendable utilizar como guía las cláusulas modelo preparadas por el Centro Internacional de Arreglo de Diferencias Relativas a Inversiones (en adelante, CIADI) ${ }^{9}$.

Tercero, es esencial que en cualquier tipo de acuerdo directo, el alcance del consentimiento y la delimitación de las disputas que las partes someten a arbitraje queden debidamente definidos. En la práctica, las operaciones de inversión extranjera pueden involucrar complejas estructuras que con frecuencia se materializan a través de varios contratos. Para citar un ejemplo, si sólo alguno o algunos de dichos contratos contienen acuerdos de arbitraje, podrían surgir dudas respecto del alcance del consentimiento y la posibilidad de llevar a arbitraje una disputa relacionada con la operación de inversión en su totalidad ${ }^{10}$.

7. Véase: Amco Asia Corp. c. Indonesia, Decisiỏn sobre jurisdicción, Caso CIAD1 No. ARB/81/1, 25 de scptiembre de $: 983$.

8. Véase: $C S O B$ c. Slovakia, Decisión de Jurisdicción, Caso CIADI No ARB/97/4, 24 de mayo de 1999.

9. Véase: Centro Internacional de Arreglo de Diferencias Relativas a Inversiones, ICSID Model Clauses: Doc. ICSID/5/Rev, 2 de febrero de 1993, en ICSID Review, No. 8.1, 1993, pp. 134-151.

10. Al respecto, véase: Duke Energz International Penu Imvestments No. I Lud. c. Peri, Laudo, Caso CIADI No. ARB/03/28, 18 de agosto de 2008; CSOB c. Slovakia, Decisión de Jurisulicción, Caso CIADI No. ARB/97/4, 24 de mayo de 1999; Dolzer, Rudolf \& Schrcuer, Christoph, Principles of International Investment Law; Oxford University Press, 2008, pp. 239-240. 


\subsubsection{Oferta de arbitraje formulada en la legislación nacional}

Los Estados receptores de inversión pueden efectuar ofertas de arbitraje de inversión a inversionistas extranjeros mediante su legislación nacional. Evidentemente, no cualquier referencia a arbitraje de inversión en leyes nacionales constituye una manifestación del consentimiento del Estado para arbitrar. Se debe estudiar cada caso en concreto para determinar si en efecto se está ante una oferta de arbitraje.

La oferta de arbitraje para los inversionistas extranjeros puede ser unívoca. Un ejemplo de este tipo de oferta se encuentra en el artículo 8(2) de la Ley 7764 de 1993 de Albania, bajo la cual: el inversionista extranjero puede someter la disputa, y la República de Albania consiente a ello, al Centro Internacional de Arreglo de Diferencias Relativas a Inversiones ${ }^{11}$. La Ley citada sirvió de fundamento para que un tribunal CIADI se declarara competente para conocer del caso Tradex Hellas c. Albania ${ }^{12}$. También podría haber una oferta menos explícita, que aún así constituya una manifestación del consentimiento del Estado. Un ejemplo ilustrativo se encuentra en el Código de Inversión de Camerún de 1990, cuyo artículo 45(1) establece que los inversionistas extranjeros tendrán derecho a solicitar que la disputa sea resuelta, entre otras opciones, mediante arbitraje de inversión $\mathrm{CIADI}^{13}$.

Las legislaciones nacionales a veces hacen referencia al arbitraje de inversión, pero son claras en que esa mención no pretende constituir una manifestación del consentimiento del Estado. Un ejemplo de lo anterior sería el caso de una disposición que establezca que las partes "podrán acordar" que sus disputas relativas a la inversión se resolverán mediante arbitraje ${ }^{1+}$. En otros

11. Lcy No. 7763 (Albania), 1993. El texto citado es una traducción libre realizada a partir del texto en inglés de la ley, que a su turno se encuentra en la decisión sobre jurisdicción del caso CIADI Tradex Hellas c. Alhania. Véase: Trader Hellas c. Albania, Decisión sobre jurisdicción, Caso ClADI No. ARB/94/2, 24 de diciembre de 1996.

12. Véasc: Tradex Hellas c. Alhania, Decision sobre jurisulieciòn, Caso ClADI No. ARB/94/2, $24 \mathrm{de}$ diciembre de 1996 .

13. Véase: Conferencia de las Naciones Unidas sobre Comercio y Desarrollo, Dispute Senlenent, International Centre for Settlement of Investment Disputes, 2.3 Consent to Arbitration. UNCTAD/EDM/Misc.232/Add 2, p. 11. Investment Law; Oxford University Press, 2008, pp. 239-240. 
casos puede haber ambigüedades que den lugar a una controversia sobre el particular. Esta última situación se presentó en el caso SPP c. Egipto, en que el demandante alegó que el artículo $8^{\circ}$ de la Ley 43 de 1974 (de Egipto) constituía una oferta de arbitraje y el Estado demandado negó haber prestado su consentimiento para arbitrar mediante dicha disposición ${ }^{15}, y$, más recientemente, en los arbitrajes que debatieron los efectos del artículo 22 del Decreto 365 de octubre de 1999 del Presidente de la República Bolivariana de Venezuela ${ }^{16}$.

Para concluir, se debe resaltar que una disposición legislativa mediante la cual se plasme la voluntad de arbitrar, no es más que una oferta del Estado al inversionista extranjero; el pacto arbitral únicamente se forma en el momento en que la oferta es aceptada por el inversionista. Por lo general, se reconoce que el inversionista acepta la oferta del Estado al iniciar un arbitraje ${ }^{17}$.

\subsubsection{Tratados Internacionales ${ }^{18}$}

Al igual que mediante ofertas contempladas en legislaciones nacionales, un Estado puede prestar su consentimiento para arbitrar diferencias relativas a inversiones mediante una oferta inserta en un tratado internacional. Es de notar que el tratado en sí no contiene el pacto arbitral, sino una oferta de cada Estado signatario a los inversionistas protegidos por el tratado. Así, no es

14. Vẻase: SCIIREUer, Christoph, The ICSID Convention. A Commentary, Cambridge University Press, 2009, pp. 200-202; SCHreuER, Christoph, "Consent to Arbitration", en Muchlinski, Peter; Ortino, Fcderico \& SCHREUER Christoph (Eds,), The Oxford Handbook of International Inestment Law, Oxford University Press, 2008, Capitulo 21, § 2. Disponible en Wcb: hutp:/icsid.worldbank org/ICSID/FrontServlet?request Type $=$ CasesRH\&actionVal=showDoc\&docld =DCI510_En\&caseld $=$ C256 (Consulta 15 de septiembre de 2012).

15. Vċase: Southern Pacific Properties (Middle East) Ltd. c. Egipto, Laudo, Caso CIADI No. ARB/84/3, 20 de mayo de 1983.

16. Véase: Mobil Corporation, Venezuela Holdings, B.V. et. àl. c. Bolivarian Republic of Venczuela, Decisión sobre jurisdicción, Caso CIADI No. ARB/07/27 de junio 10 de 2012. CEMEX Caracas Imestments B.V. and CEMEX Caracas Investments II B.V. c. Bolivarian Republic of Venezucla, Caso CIADI No. ARB/08/15, Decisión sobre jurisdicción de diciembre 30 del 2010.

17. Véase: Tradex Hellas c. Albania, Decisión sobre jurisdicción, Caso CIADI No. ARB/94/2, 24 de diciembre de 1996; Schreuer, Christoph, The ICSID Convention. A Commentary, Cambridge University Press, 2009, pp. 202-205.

18. Por tratados internacionales, se hace referencia tanto a instrumentos bilaterales como multilaterales 
sino hasta que el inversionista -nacional de uno de los Estados signatarios del tratado, distinto al Estado receptor de la inversión-acepta la oferta, que se forma el acuerdo de las partes para arbitrar.

Un gran número de arbitrajes de inversión encuentran su fundamento en tratados internacionales que, con notoria frecuencia, contienen ofertas de arbitraje ${ }^{19}$. Un ejemplo de una oferta de arbitraje contenida en un tratado internacional es el artículo 11 del Convenio entre la República de Colombia y la Confederación Suiza sobre la Promoción y la Protección Recíproca de Inversiones, que dice:

(1) Si un inversionista de una Parte considera que alguna medida aplicada por la otra Parte es inconsistente con una obligación de este Acuerdo, y esto causa algún daño o pérdida a él o a su inversión, él podrá solicitar consultas con miras a que se pueda resolver el asunto amigablemente.

(2) Cualquier asunto que no haya sido resuelto dentro de un periodo de seis meses desde la fecha de la solicitud escrita para consultas, podrí ser remitido a las cortes o tribunales administrativos de la Parte concerniente o al arbitraje internacional. En el último caso, el inversionista tendrá la opción de escoger entre alguno de los siguientes:

(a) El Centro Internacional de Arreglo de Diferencias Relativas a Inversiones (CIADI), establecido por el Convenio sobre Arreglo de Diferencias, Relativas a Inversiones entre Estados y Nacionales de otros Estados, abierto para firma en Washington, el 18 de marzo de 1965 ("Convenio de Washington"); $y$

(b) Un tribunal ad-hoc que, a menos de un acuerdo distinto entre las partes de la disputa, deberá establecerse bajo el Reglamento de Arbitraje de la Comisión de las Naciones Unidas para el Derecho Mercantil Internacional (CNUDMI).

(3) Cada Parte da su consentimiento incondicional e irrevocablemente al sometimiento de una disputa de inversión a un arbitraje internacional, de acuerdo al párrafo 2 anterior... ${ }^{20}$.

19. Para algunos ejemplos, véase: Conferencia de las Naciones Unidas sobre Comercio y Desarrollo, Dispute Setrlement, International Centre for Settlement of Investment Disputes, 2.3 Consent to Arbitration, UNCTAD/EDM/Misc.232/Add.2, p. 17.

20. Convenio cntre la República de Colombia y la Confederación Suiza sobre la Promoción y la Protección Reciproca de Inversiones, 17 de mayo de 2006, articulo 11. 
Por otra parte, en línea con el razonamiento expuesto supra, es muy importante resaltar que no toda referencia en un tratado internacional a arbitraje de inversión constituye una oferta de arbitraje de parte de los Estados signatarios. El alcance del consentimiento de los estados puede variar considerablemente de un tratado a otro. Así, el texto de cada tratado se debe analizar con cuidado con el fin de determinar si en efecto contiene una oferta de arbitraje para inversionistas extranjeros que se encuentren cubiertos por el tratado y, de ser el caso, el alcance de dicho consentimiento ${ }^{21}$.

Al igual que con las ofertas contenidas en legislaciones nacionales, por lo general se reconoce que el inversionista acepta la oferta del Estado al iniciar un arbitraje; sin embargo, el inversionista también podría aceptar la oferta con anterioridad a que se dé inició al arbitraje $e^{22}$.

\subsection{Las partes en el proceso}

Mientras que en los arbitrajes comerciales internacionales los demandantes y demandados suelen coincidir con las partes en un contrato, sin tener otras características con fundamento en las cuales puedan trazarse distinciones generales respecto de otros procesos, en el arbitraje de inversión el demandante es típicamente un inversionista extranjero (2.2.1) y el demandado es en principio el Estado receptor de la inversión (2.2.2) ${ }^{23}$.

\subsubsection{Inversionista extranjero}

En relación con el demandante en un arbitraje de inversión, debe comenzarse por reconocer que no existe una definición uní-

21. Para un estudio detallado sobre este particular, véase: Douglıs, Zachary, The International Law of Investment Claims, Cambridge University Press, 2009, pp. 234 y ss.

22. Véase: SCiteutr, Christoph. The ICSID Convention. A Commentary, Cambridge University Press, 2009, pp. 211-214.

23. Dolzer, Rudolf \& SChreuer, Clristoph, Principles of International Investment Law, Oxford University Press, 2008, p.. 233. 
voca de inversionista extranjero. El significado del concepto varía según el instrumento del que se derive la jurisdicción del tribunal.

Cuando dicho instrumento es un TBI o un capítulo de inversión de un TLC, generalmente se exige que el inversionista sea nacional de uno de los Estados contratantes. Por ejemplo, el Capítulo X del TLC Colombia-Estados Unidos dispone en su artículo 10.28:

[I Inversionista de una Parte significa una parte o una empresa del Estado de la misma, o un nacional o empresa de la Parte, que intenta realizar, a través de acciones concretns, está realizando o ha realizado una inversión en el territorio de otra Parte; considerando, sin embargo, que una persona natural que tiene doble nacionalidad se considerará exclusivamente un nacional del Estado de su nacionalidad dominante y efectiva ${ }^{24}$.

En tratándose de leyes de protección de inversiones, generalmente se utiliza una terminología más amplia, que no limita el concepto de inversionista extranjero a aquellos que provienen de un Estado determinado. Por ejemplo, en Albania, la Ley No. 7764 de 1993 disponía:

2. Inversionista extranjero significa: a) cualquier persona natural que sea ciudadana de un país extranjero, ob) cualquier persona natural que sea ciudndana de la República de Albania y tenga su domicilio permanente en un país extranjero, o c) cualquier persona jurídica que haya sido incorporada o constituida bajo las leyes de un país extranjero que directa o indirectamente busque realizar o esté realizando una inversión en el territorio de ln República de Albania bajo sus leyes o haya realizado una inversión bajo las leyes vigentes en el periodo de tiempo corrido del 31 de julio de 1990 en adelante $e^{25}$.

24. Tratado de Libre Comercio Colombia-Estados Unidos, 22 de noviembre de 2006, capítulo 10, artículo 10.28 .

25. Ley No. 7763 (Albania), 1993. El texto citado es una traducción libre realizada a partir del texto cn inglès de la ley, que a su tumo se encuentra en la decisión sobre jurisdieción del caso CIADt Trader Hellas c. Alhania, Véasc: Trader Hellas c. Alhania, Decisión sobre jurisdicción, Caso CIADI No. ARB/94/2, 24 de diciembre de 1996. 
Finalmente, cuando el consentimiento para acudir a arbitraje se ha manifestado en un contrato de inversión, el inversionista extranjero será en principio quien contrata con el Estado receptor de la inversión; así pues, se tratará de un sujeto claramente definido, de manera similar a como ocurriría en un pacto arbitral de carácter inserto en un contrato comercial ${ }^{26}$.

\subsubsection{Estado}

Como se señaló en los párrafos anteriores, el demandado en un arbitraje de inversión suele ser el Estado receptor de la inversión; sin embargo, también puede darse el caso de arbitrajes de inversión en que se demande a algunos organismos públicos de dicho Estado.

Por ejemplo, el artículo 25 de la Convención de Washington de 1965 utiliza las expresiones "...Estado Contratante (o cualquiera subdivisión política u organismo público de un Estado Contratante acreditados ante el Centro por dicho Estado) ${ }^{\prime 27}$. Esta disposición fue objeto de controversia en el conocido caso Cable Televisión c. San Cristóbal y Nieves, en que el demandante había celebrado un contrato de inversión con la Administración de la Isla de Nieves (en adelante, AIN) que contenía un pacto para arbitraje CIADI. El tribunal halló que la AIN era una subdivisión política de San Cristóbal y Nieves, país que a su turno era parte de la Convención de Washington. Sin embargo, dado que la AIN no había sido acreditada por el Estado ante el CIADI, los árbitros se declararon faltos de jurisdicción ${ }^{28}$. Otro ejemplo se encuentra en Noble Energy c. Ecuador, en que un tribunal CIADI afirmó: "Ecuador acreditó a Conelec ante el Centro el 21 de agosto de 2002 para los efectos del artículo 25 del Convenio CIADI y Cone-

26. Respecto de los llamados contratos de inversión, vénse: Bistor, Doak; Crawford, James \&e ReIsMan, W. Michacl, Foreign Investmen Disputes. Cases, Materials and Commentary, Kluwer Law International, 2005, pp. 216-313.

27. Convenio sobre Arreglo de Diferencias Relativas a Inversiones entre Estados y Nacionales de Otros Estados, 18 de marzo de 1965, articulo 25.1.

28. Véase: Cable Televisión c. San Cristóbal y Nieves, Laudo, Caso ClADI No, ARB/95/2, 13 de enero de 1997. 
lec debe entonces considerarse como un organismo público de la República del Ecuador"29.

Estos ejemplos bastan para mostrar que, si bien el demandado en un arbitraje de inversión en principio es el Estado, también pueden demandarse algunos órganos del Estado o subdivisiones políticas del mismo, bajo ciertas circunstancias.

Finalmente, vale la pena resaltar que, aunque generalmente el inversionista es el demandante en el arbitraje de inversión, siendo el Estado receptor de la inversión el demandado, en algunos casos se ha discutido si el Estado podría presentar una demanda de reconvención contra el inversionista. En ciertas decisiones se ha respondido dicho interrogante afirmativamente ${ }^{30}$.

\subsection{Objeto de la controversia}

En un arbitraje comercial internacional, la controversia que debe resolver el tribunal generalmente está relacionada con una relación jurídica de derecho privado, sin perjuicio de que pueda haber arbitrajes comerciales sobre, por ejemplo, contratos estatales. En el arbitraje de inversión, la controversia concierne una inversión e involucra el ejercicio del poder de imperio del Estado. Sin embargo, el objeto de la controversia depende sobremanera del instrumento que sirva como fuente de jurisdicción al tribunal, por dos razones.

Primero, ese instrumento es el que define qué se entiende por inversión. Por ejemplo, el TLC entre Colombia y los Estados Unidos dispone:

29. Nohle Energy \& Afachala Power Cia. Lida. c. Ecuador \& Consejo Nacional de Elcctricidad, Decisión sobre Jurisdicción, Caso CIADI No. ARB/05/12, 5 de marzo de 2008, 163.

30. Sobre la posibilidad de que el Estado presente una demanda reconvencional contra el inversionista, véase: Spyridon Roussalis c. Rumania, Laudo, Caso ClADI No. ARB/06/1, 7 de diciembre de 2011; Saluka c. Repuiblica Checa, Decisión de jurisdicción sobre la demanda reconvencional de la República Checa, Caso CNUDMI. 7 de mayo de 2004; Alex Genin, Eastern Credir Limited, Inc. \& A.S. Baltoil c. Estonia, Laudo, Caso CIADI No. ARB/99/2, 25 de junio de 2001; Mfaritime International Nominees Establishment c. Guinca, Laudo, Caso CIADI No. ARB/84/4, 6 de enero de 1988, Atluntic Triton c. Guinea, Laudo, Caso ClADI No. ARB/84/1, 21 de abril de 1986. 
"[i]nversión significa todo activo de propiedad de un inversionista o controlado por el mismo, directa o indirectamente, que tenga las características de una inversión, incluyendo caracteristicas tales como el compromiso de capitales y otros recursos, la expectativa de obtener ganancias o utilidades, o la asunción de riesgo" ${ }^{\prime 31}$.

Otros instrumentos, como el TLC entre Colombia y Canadá, traen un listado de aquello que se considera una inversión, así como una lista de lo que no se entiende comprendido dentro del concepto de inversión ${ }^{32}$. Así pues, la definición de inversión varía según el tratado, la ley de inversión extranjera o el contrato de inversión aplicable.

Segundo, la relación que debe tener la controversia con la inversión es determinada de manera diferente en cada instrumento. En relación con este punto, la doctrina ha identificado cuatro categorías. La primera agrupa los instrumentos que se refieren a "todas" o "cualquiera" de las controversias relacionadas con una inversión; la segunda incluye aquellos que aluden a controversias que surjan de o se relacionen con una autorización de inversión, un acuerdo de inversión o la supuesta violación de cualquier derecho conferido, creado o reconocido por el instrumento en relación con una inversión cubierta; el tercer grupo restringe el objeto del arbitraje a violaciones del instrumento que contiene la manifestación de voluntad del Estado (v.gr., el TBI); finalmente, el cuarto grupo limita el objeto del arbitraje a controversias acerca del quantum a pagar en caso de una expropiación ilícita ${ }^{33}$.

Así pues, el objeto de la controversia en los arbitrajes de inversión concierne una inversión; en los arbitrajes comerciales, el objeto del proceso varía significativamente de un arbitraje a otro.

31. Tratado de Libre Comercio Colombia-Estados Unidos, 22 de noviembre de 2006, capitulo 10, articulo 10.28 .

32. Véase: Tratado de Libre Comercio Colombia-Canada, 21 de noviembre de 2008, capitulo VIIl, articulo 838.

33. Véase: Douglas, Zachary, The International Law of Investment Claims, Cambridge University Press, 2009, p. 234. 


\subsection{Derecho aplicable}

La ley sustantiva que aplica un tribunal comercial internacional es, en principio, la acordada por las partes. Ese derecho corresponderá típicamente a un sistema jurídico nacional, si bien es posible acordar válidamente la aplicación de un cuerpo de reglas de origen no nacional (v.gr., los principios Unidroit). En ese sentido, la Ley 1563 de 2012 dispone: "El tribunal decidirá de conformidad con las normas de derecho elegidas por las partes" ${ }^{34}$. La expresión normas de derecho, tomada del artículo 28 de la Ley Modelo de la CNUDMI, implica que las partes pueden escoger el ordenamiento jurídico de un Estado como ley aplicable, pero también normas ajenas a toda legislación estatal ${ }^{35}$.

En el arbitraje de inversión el derecho aplicable es generalmente el derecho internacional público; decimos generalmente, porque en ciertos casos puede ser aplicable un derecho nacional o un cuerpo de normas de origen no estatal, bien sea de manera exclusiva o conjuntamente con el derecho internacional público ${ }^{36}$.

En ese orden de ideas se ha expresado que:

Las inversiones extranjeras se encuentran reguladas por reglas tanto internacionales como nacionales. Existe un cuerpo considerable de derecho internacional sustantivo que protege a los inversionistas extranjeros. Este [derecho encuentra su fuente en] tratados, [y está] contenido principalmente en TBIs, pero también en tratados multilaterales como el TLCAN o la Carta de la Energía. Pero también hay una buena porción de derecho consuetudinario que conserva relevancia. Este derecho internacional consuetudinario incluye varios aspectos de responsabilidad del Estado y asuntos tales como dene-

34. Ley 1563 de 2012, 12 de julio de 2012, articulo 101.

35. Véase: Born, Gary, International Commercial Arbitration, Paises Bajos, Wolıers Kluwer, 2009, p. 2228.

36. Véase: Douglas, Zachary, The International Law of Investment Clains, Cambridge University Press, 2009. pp. 40-125; Dolzer, Rudolf \& SCHReuer, Christoph. Principles of International Imestment Law, Oxford University Press, 2008, pp. 265-27I. En relaciỏn con la ley aplicable en arbitrajes ClADI, véase: SCuREuer, Christoph, The ICSID Convention. A Commentary; Cambridge University Press, 2009, pp. 545-639. Respecto de la ley aplicable a contratos de inversión, véase: DoLzER, RuDOLf \& Schreutr, Christoph, Principles of International Imvestment Law, Oxford University Press, 2008, pp. 73-74. 
gación de justicia, el derecho relativo a las expropiaciones y reglas respecto de la nacionalidad de individuos y compañías. Sin embargo, los inversionistas también están sujetos al derecho doméstico del Estado receptor. Hay legislación relevante como derecho comercial, derecho societario, derecho administrativo, derecho laboral, derecho tributario, regulaciones cambiarias, derecho inmobiliario, y otras muchas arens del sistema juridico del Estado receptor [... $]^{37}$.

Dicho lo anterior, es posible concluir que, cuando un tribunal arbitral internacional decide una controversia de conformidad con el derecho internacional público, en principio se tratará de un arbitraje de inversión. Sin embargo, la ley aplicable en un arbitraje de inversión puede ser diferente al derecho internacional público.

\subsection{El procedimiento arbitral}

El procedimiento en un arbitraje comercial internacional y en uno de inversión no es necesariamente diferente ${ }^{38}$. De hecho, un arbitraje de inversión puede llevarse bajo reglamentos como el de la CNUDMI, el de la Corte Internacional de Arbitraje de Londres (en adelante, LCIA), o el de la Cámara de Comercio Internacional (en adelante, CCI), por solo mencionar algunos ejemplos. En ese sentido, el artículo IX del TBI Colombia-Reino Unido dispone:

\section{[...] El inversionista y la parte contratante partes de la controversin podrán acordar referir la controversia a alguno de los siguientes:}

37. Traducción libre. El texto original en inglés dice: "[I]oreign investments are regulated by international as well as national rules. There is a considerable body of substantive international law protecting foreign investors. It consists of treaty law, contained mostly in BITs, but also multilateral treaties such as NAFTA and the Energy Charter Treaty. But there is also a good deal of customary international law that remains relevant. This customary international law includes various aspects of state responsibility and such issues as denial of justice, the law on expropriation and rules relating to the nationality of individuals and corporations. But investors are also subject to the host state's domestic law. There is relevant legislation like commercial law, company law, administrative law, labour law, tax law, forcign exchange regulations, real estate law, and many other areas of the host state's legal systern". DoLzER, Rudolf \& Scireuer, Christoph., Principles of International Investment Law, Oxford University Press, 2008, p. 265.

38. Sin cmbargo, el procedimiento en un arbitraje internacional -comercial o de inversión-si suele ser muy distinto del que se sigue en los procesos judiciales y en el arbitraje doméstico. Véase: Btsıor, Doak: Crawford, James \& Reissin, W. Michacl, Foreign Investment Disputes. Cases, Materials and Commentan: Kluwer Law International, 2005, p. 16. 
(a) El Centro Internacional de Arreglo de Diferencins Relativas a Inversiones (teniendo en cuenta las disposiciones aplicables del Convenio sobre el arreglo de diferencias relativas a inversiones entre Estados y Nacionales de Otros Estados, abierto a la firma en Washington, D.C. el 18 de marzo de 1965 y el Mecanismo Complementario para la Administración de Procedimientos de Conciliación, Arbitraje y Comprobación de hechos);

(b) La Corte de Arbitraje de la Cámara de Comercio Internacional;

(c) Un árbitro internacional o tribunal de arbitraje ad hoc que será designado por un acuerdo especial o establecido de conformidad con las Reglas de Arbitraje de la Comisión de las Naciones Unidas para el Derecho Mercantil Internacional; o

(d) Un tribunal conformado de acuerdo con las Reglas de Arbitraje de la institución de arbitraje de la Parte Contratante en cuyo territorio se renlizó la inversión, según lo especificndo en el Anexo 1 de este Acuerdo ${ }^{39}$.

A pesar de la variedad de reglamentos de arbitraje que pueden regir el procedimiento en un arbitraje de inversión, lo cierto es que un reglamento puede estar diseñado para ser utilizado exclusivamente en arbitrajes de inversión; ese es el caso del el Reglamento del CIADI. Por ello podría aseverarse que, si bien todo arbitraje CIADI es de inversión, no todo arbitraje de inversión es CIADI $^{40}$.

\section{El ARBITRAJE de INVERSión Y LA LEY 1563 DE 2012}

Habiendo trazado una distinción general entre los arbitrajes comerciales internacionales y los arbitrajes de inversión, cabe preguntarse si un arbitraje de inversión puede estar sujeto a la Ley 1563 de 2012. El punto de partida para la respuesta a dicho interrogante debe ser, naturalmente, el artículo 62 del nuevo Estatuto de Arbitraje Internacional, de conformidad con el cual las normas

39. Acuerdo Bilateral para la Promoción y Protección de Inversiones Colombia - Reino Unido, 19 de mayo de 2009, articulo IX. Es preciso iener en cuenta que este tratado no habia entrado en vigencia a la fecha de presentación de este articulo.

40. Para una descripción general del procedimiento en un arbitraje ClADI, véase: DOLZer, RudOLF \& SCIseruer, Christoph, Principles of International Investment Law, Oxford University Press, 2008, pp. 257, ss. 
de la ley aplican únicamente a arbitrajes internacionales cuya sede se encuentre en el país, salvo por algunas disposiciones que conciernen la ejecución en Colombia de laudos extranjeros y de medidas cautelares dictadas por tribunales cuya sede se encuentra fuera del país, entre otros asuntos ${ }^{41}$.

Si el elemento definitorio de la aplicación de la Ley 1563 de 2012 es la sede del tribunal, entonces habría que reformular el interrogante objeto de estudio, en los siguientes términos: ¿puede un tribunal arbitral de inversión tener sede en Colombia? La respuesta ha de ser afirmativa. Arbitraje de inversión no es sinónimo de arbitraje deslocalizado o arbitraje sin sede. Por ejemplo, si un TBI prevé que una controversia entre un inversionista extranjero y el Estado receptor de la inversión puede someterse a arbitraje bajo el Reglamento de Arbitraje de la CCI, ese arbitraje tendría su sede en el territorio de un Estado; en consecuencia, el laudo resultante podría ser anulado por los jueces competentes de la sede y requeriría de exequátur para ser ejecutado fuera del país donde está localizada la sede ${ }^{42}$.

Existe, sin embargo, una excepción de gran importancia práctica. El artículo 53(1) de la Convención de Washington de 1965 dispone:

El laudo será obligatorio para las partes y no podrá ser objeto de apelación ni de cualquier otro recurso, excepto en los casos previstos en este Convenio. Las partes lo acatarán y cumplirán en todos sus términos, salvo en la medida en que se suspenda su ejecución, de acuerdo con lo establecido en las correspondientes cláusulas de este Convenio ${ }^{43}$.

41. Véase: Ley 1563, 12 de julio de 2012, articulo 62, incisos 1 \& 2 .

42. El autor ya ha tenido oportunidad de analizar detalladamerie el concepto de sede y sus consecuencias sobre la "nacionalidad" del laudo arbitral. Véase: Eduardo ZuL.ETA \& Alberto ZULETA, "La relevancia de la llamada "nacionalidad de la sentencia arbitral" en la Convención de Nueva York", en Revista Ecuatoriana de Arbitrajc, Cevallos Editora Juridica, 2010, pp. 323-352.

43. Convenio sobre Arreglo de Diferencias Relativas a Inversiones entre Estados y Nacionales de Otros Estados, 18 de marzo de 1965, artículo 53.1. 
En relación con esta disposición, se ha explicado que:

La Convención prevé una serie de procedimientos de impugnación y revisión en los artículos 49(2) (complementación y rectificación), 50 (interpretación), 51 (revisión) y 52 (anulación). El sistemn de revisión bajo la Convención es autocontenido y no admite ninguna forma de revisión externa. Este principio también se extiende a la etapa de reconocimiento y ejecución de los laudos CIADI. Una corte o autoridad doméstica ante la cual se persiga el reconocimiento y ejecución está limitada a la determinación de la autenticidad del laudo. No puede reexaminar la jurisdicción del tribunal. No puede reexaminar el laudo en cuanto al fondo. Tampoco puede examinar la justicin y propiednd del procedimiento [surtido] ante el tribunal Cindi $^{\text {H. }}$.

No sobra añadir que existen dos tipos de arbitrajes CIADI. El primer grupo corresponde a los arbitrajes que se encuentran cobijados por la Convención de Washington de 1965, caso en el cual el laudo no está sujeto a recurso alguno ante cualquier corte nacional. Se trata de lo que algunos autores llaman un arbitraje sin sede que da lugar a un laudo anacional. En el segundo grupo están los arbitrajes que, si bien no están cobijados por la Convención, se someten al Reglamento del CIADI y son administrados por el Centro, de conformidad con el Mecanismo Complementario de 1978. En esta última hipótesis, el arbitraje sí tiene una sede y laudo que resulte del proceso puede estar sujeto a anulación y requiere de exequátur para ser ejecutado fuera de la sede $e^{45}$.

Ahora bien, es preciso agregar que el hecho de que las audiencias de un arbitraje de inversión tengan lugar en Colombia, no significa que la sede del tribunal se encuentre en el país; la

44. Traducción libre. El texto original en inglés dice: “[t]he Convention provides for a number of remedies and review procedures in Arts. 49(2) (supplementation and rectification), 50 (interpretation), 51 (revision) and 52 (annulment). The system of review under the Convention is self-contained and does not permit any extemal revicw. This principle also extends to stage of recognition and enforcement of ICSID awards. A domestic court or authority before which recognition and enforcement is sought is restricted to ascertaining the award's authenticity. It may not re-examine the ICSID tribunal's jurisdiction. It may not re-examine the award on the merits. Nor may it examine the fairness and propriety of the proceedings before the ICSID tribunal". Schreuer. Christoph, The ICSID Convention. A Conmentary, Cambridge University Press, 2009, p. 1139.

45. Sobre este punto, véase: SCIIREuer. Christoph. The JCSID Convention. A Commentan;, Cambridge University Press, 2009, p. 1139. 
sede es un concepto jurídico antes que físico. En ese sentido, se ha explicado con acierto:

La distinción entre el lugar o "sede" del arbitraje y la locación [física] de los procedimientos o de la deliberación es trillada. Algunos participantes inexpertos en arbitraje internacional podrian estar inicialmente confundidos (y algunos más experimentados, pretender estar confundidos) acerca del hecho de que el lugar o "sede" arbitral no es el lugar físico sino el vínculo, la "vinculación" o factor de conexión a un sistema procesal determinado o lex arbitri del Estado donde está situada la "sede". Es también un principio aceptado que, por conveniencia $u$ otras razones, las audiencins y deliberaciones pueden tener lugar en un lugar diferente a la "sede" del arbitraje ${ }^{46}$.

Así, por ejemplo, en un arbitraje CIADI cobijado por la Convención de Washington de 1965, las audiencias podrían tener lugar en Bogotá; más aún, existe un convenio para el efecto entre la Cámara de Comercio de Bogotá y el CIADI ${ }^{47}$. A pesar de ello, en tales casos, no podría considerarse que por esa circunstancia el arbitraje tiene sede en el país.

Finalmente, la Ley 1563 de 2012 aplicaría al recurso de anulación de laudos en arbitrajes de inversión que tengan como sede a Colombia, y al reconocimiento y ejecución de laudos proferidos en arbitrajes de inversión diferentes de aquellos que se profieran por tribunales CIADI al amparo de la Convención de Washington de 1965.

46. Traducción libre. El texto original en inglés dice: "[t]he distinction between the place or 'seat' of arbitration and the actual location of the proceedings or deliberation is a trite one. Some participants inexperienced in international arbitration might initially be confused (and some more experienced sometimes pretend to be confused) about the fact that the place or 'seat' of arbitration is not the physical location but the link, the 'rettachement' or connecting factor to a given procedurat order or 'Iex arbitri' of the State where the 'seat' is situated. It is also an oceepted principle that, for convenience or other reasons, hearings and deliberations may be held elsewhere than at the 'seat' of arbitration". A. Criverallo, "The Place or 'Seat' of Arbitration (Possibility, and/or Sometimes Necessity of its Transfer?) Some Remarks on the Award in ICC Arbitration No. 10'623, en ASA Bulletin, No. 21, marzo de 2003. p. 112 .

47. Véase: Cámara de Comercio de Bogotá, Membresias y Comenios. Disp̧onible en Web: http://www.cacccb.org.co/contenido/contenido.aspx?catID=155\&conID=510. (Consulta 15 de septiembre de 2012). 


\section{Conclusión}

Este artículo ha buscado analizar la relación existente entre el nuevo Estatuto de Arbitraje Internacional, aprobado mediante la Ley 1563 de 2012, y el arbitraje de inversión. Con tal fin se ha comenzado por establecer las principales diferencias entre los arbitrajes comerciales y los de inversión. Como el lector acucioso habrá notado, al enunciar las características de dichas categorías, se ha evitado utilizar un lenguaje tajante.

La razón es que se trata de características y diferencias que se presentan usualmente, pero no en todos los casos; de hecho, la distinción entre ambos tipos de arbitraje debe visualizarse, más que como una división entre blanco y negro, como una escala de grises. En un extremo de dicha escala se ubicarían los arbitrajes que claramente son arbitrajes de inversión; piénsese, por ejemplo, en un arbitraje CIADI entre un Estado y un inversionista extranjero, por la violación de un TBI y en que el tribunal debe decidir la controversia conforme al derecho internacional público. En el otro extremo se situarían los arbitrajes que claramente son arbitrajes comerciales internacionales, como lo sería un arbitraje bajo el Reglamento de Arbitraje CCI, entre dos particulares y por el incumplimiento de un contrato comercial. En el medio aparecerían otros arbitrajes que tienen elementos de ambas categorías, que en ocasiones son difíciles de situar y dan lugar a complejas discusiones sobre la competencia del tribunal.

Habiendo establecido en estos términos los criterios de diferenciación entre los arbitrajes comerciales internacionales y los arbitrajes de inversión, podemos concluir que la Ley 1563 de 2012 no aplica a los arbitrajes de inversión CIADI que se adelanten al amparo de la Convención de Washington de 1965, aunque las audiencias del arbitraje correspondiente se celebren en Colombia. Tampoco aplica al reconocimiento y ejecución de laudos proferidos en arbitrajes CIADI al amparo de la citada Convención. 
Se aplica, por el contrario, a los arbitrajes CIADI adelantados al amparo del Mecanismo Complementario de 1978, cuando tales arbitrajes tengan sede en Colombia, y al reconocimiento y ejecución de laudos proferidos fuera de Colombia bajo el referido mecanismo complementario.

Finalmente, la Ley 1563 de 2012 se aplica a todos los demás arbitrajes de inversión que tengan una sede ubicada en el territorio nacional colombiano (v.gr., arbitrajes de inversión bajo el Reglamento de Arbitraje CCI o bajo las Reglas de Arbitraje de la CNUDMI) y al reconocimiento y ejecución de laudos proferidos fuera de Colombia bajo cualesquiera reglas de arbitraje, con excepción, se reitera, de los laudos proferidos en arbitrajes CIADI al amparo de la Convención de Washington de 1965. 
